\title{
Comparison of Cervical Flexor Muscles Thickness During Cranial-Cervical Flexor Exercise According to Pressure Levels and Eye Directions in Healthy Subjects
}

\author{
Jong Sung Chang', Jeon Hyeong Lee² \\ 'Department of Physical Therapy, Yeungnam University College; ${ }^{2}$ Department of Physical Therapy, Daegu Health College, Daegu, Korea
}

\begin{abstract}
Purpose: The purpose of this study is to investigate differences of cervical flexor muscle thickness (i.e., sternocleidomastoid muscle and deep cervical flexor muscles) depending on levels of pressure bio-feedback unit and eye directions during cranial-cervical flexor exercise in healthy subjects.

Methods: A total of 30 subjects (12 males and 18 females) who had no medical history related to musculoskeletal and neurological disorders were enrolled in this study. They were instructed to perform cranial-cervical flexion exercise with adjustment of five different pressures (i.e., $22 \mathrm{mmHg}, 24 \mathrm{mmHg}, 26 \mathrm{mmHg}, 28 \mathrm{mmHg}$, and $30 \mathrm{mmHg}$ ) using a pressure biofeedback unit, according to three different eye directions (i.e., $0^{\circ}, 20^{\circ}$, and $40^{\circ}$ ). Muscle thickness of sternocleidomastoid muscle and deep cervical flexor muscles was measured according to pressure levels and eye directions using ultrasonography.

Results: In results of muscle thickness in sternocleidomastoid muscle and deep cervical flexor muscles, the thickness of those muscles was gradually increased compared to the baseline pressure level $(22 \mathrm{mmHg})$, as levels in the pressure biofeedback unit during cranial-cenvical flexion exercise were increasing. In addition, at the same pressure levels, muscle thickness was increased depending on ascending eye direction. Conclusion: Our findings showed that muscle thickness of sternocleidomastoid muscle and deep cervical flexor muscles was generally increased during cranial-cervical flexion exercise, according to increase of eye directions and pressure levels. Therefore, we suggested that lower eye direction could induce more effective muscle activity than the upper eye direction in the same environment during cranial-cervical flexion exercise.
\end{abstract}

Keywords: Cranio-cervical flexion, Eye direction, Pressure level, Ultrasonography

\section{서 론}

경추(cervical)는 두개골과 체간을 연결해주는 7개의 뼈와 디스크로 구성되어 있는데 머리를 지지하고 안정성을 유지하는 기능을 수행하 며, 척추 중에서 운동성이 가장 큰 관절을 이루고 있다. 경추 주변의 근육작용들 중에서 가장 중요한 부분은 심부에 위치한 척추 근육들 인 긴목근(longus colli)과 긴머리근(longus capitis)인데, 이 근육들은 동적으로 유사한 기능을 수행하여 목의 수직 안정성을 제공하는 중 요한 구조물이며, 목뼈의 앞 굽음과 각 관절을 지지하고 고정하는 역 할을 한다.1-3 경추에서 일어나는 다양한 자유도의 운동 중에서 심부 목 굽힘근에 의한 머리-목 굽힘(cranio-cervical flexion) 동작이 가장 많이 유발된다. 머리-목 굽힘 운동은 긴목근과 긴머리근과 같은 심부
목 굽힘근을 활성화하고, 그 동작이 수행되고 있는 동안 표면근육인 목빗근과 앞목갈비근의 해부학적 활동을 평가하는데 적합하다고 하 였다.2,4 심부 목 굽힘근은 목의 올바른 자세를 유지하기 위해 머리, 등, 허리에서 균형 유지에 기여하며, 여러 방향으로 머리를 움직이는 동 안 머리 무게를 지지하기 위해 공동으로 협력하여 강한 근수축력 보 다는 낮은 강도의 정적 근지구력에 의해 목을 지지하고 고정하여 안 정성을 제공하는 역할을 한다. ${ }^{4}$

최근 목 심부 근들의 분석에 많은 관심이 쏠리고 있지만, 아직까지 심부에 위치한 척추의 근육들의 분석은 쉽지가 않다. 그럼에도 불구 하고 이러한 근육들은 몸 속 아주 깊숙이 위치하기 때문에 촉진이나 도수 검사 같은 전통적인 방식으로 그 기능을 평가하기엔 정확성이 떨어진다. 한편, 근육을 검사하는 대표적인 방법으로 근전도 검사 
(electromyography)와 초음파 촬영이 있는데, 근전도 검사는 근육 전 기 신호의 발생 기록과 분석을 하는 장비로써, 근세포가 흥분하여 수축작용을 일으킬 때 발생하는 미세한 활동 전위를 증폭시켜 기록 한 것을 나타낸다. 그리하여 근 활동 상태나 중추신경의 지배 상황을 파악할 수 있다. 이러한 신호를 시선의 각도적 정보로 기록할 수 있는 특성이 있어 신경질환이나 예후 진단 등 임상학적 측면과 생체역학 운동 생리학 연구 분야에서 많이 사용되고 있지만, 심부 근육을 측정 하기에는 어려운 점이 많다. 그러나 실시간 초음파 측정(real-time ultrasonography)은 대상 환자가 편안한 상태에서 간편하게 검사할 수 있으며, 넓은 적용범위와 낮은 비용으로 인체에 무해하기 때문에 근 육의 영상 검사 중 가장 기초가 되는 검사법이다. 또한 근육들을 실시 간으로 관찰할 수 있으며 근육의 측정도 이완 상태뿐만 아니라 다양 한수축상태에서도 적용 가능한 장점이 있다.5-7

심부 목 굽힘근은 직접 촉진하거나 표면 근전도를 적용하기는 어 렵지만 초음파 측정도구는 근육수축의 과정을 시선의 각도적인 피 드백 자료로써 실시간으로 제공할 수 있어 유용하다. 최근 심부 목근 육군의 초음파 영상에 관한 다양한 연구들이 제시되고 있는데, Greig 등 8 은 정보 매체의 높이에 따라 목근육의 활성도가 달라진다고 하였 고, 미국 산업안전보건청과 캐나다 국립표준협회는 컴퓨터 모니터가 시선 높이에서 수직선상으로 2-15도 정도 기울어진 위치에 놓여 질 때, 목 근육들의 자세적인 부하를 줄일 수 있다고 하였다.9,10 또한 $\mathrm{Ku}-$ $\operatorname{mar}^{11}$ 는 컴퓨터 모니터의 중심부가 눈의 수평선상에서 35 도 이하로 기울어졌을 때 목빗근의 근 활성도가 낮게 나타난다고 보고하였다. 특히 Turville 등 12 은 눈의 수평선상에서 컴퓨터 모니터의 중심부까지 의 시선의 각도 15 도와 40 도를 비교하는데, 그 결과 시선의 각도 40 도 에서 근 활성도와 근 피로도가 떨어진다고 하였다.

인간의 정상적인 시야 범위는 코쪽 60 도, 귀쪽 90 도에서 95 도, 위쪽 50 도에서 60 도, 아래쪽 70 도에서 75 이다. ${ }^{13}$ 각각의 대상자들의 시선의 범위는 다르기 때문에 Turville 등르는 눈의 수평선상에서 중심부까지 의 시선의 각도 15 도와 40 도를 비교하였는데, 본 실험에서는 시선의 각도를 최대 40 도로 하여 0 도, 20 도, 40 도로 설정하였다. 본 연구에서 는 압력 바이오 피드백 장비를 이용하여 머리-목 굽힘 운동을 하는 동안, 시선의 각도에 따른 목 굽힘에 관련된 근육군들의 근육 두께가 어떻게 변화하는지를 알아보고자 하였다.

\section{연구방법}

\section{1. 연구 대상}

본 연구의 대상자는 대구 소재의 $\mathrm{D}$ 대학교 물리치료과에 재학 중인 20 대의 대학생 남녀 30명(남자; 12 명, 여; 18 명)을 대상으로 하였다. 모 든 대상자는 최근 3 년 동안 목 주위에 통증을 호소하지 않았고 목 주
위의 정형외과적 질환 및 전신의 신경학적 질환이 없는 자를 선정하 였다. 대상자는 실험에 참가하기 전에 연구의 목적과 절차에 대해 충 분히 설명을 들었고, 자발적 동의 후에 실험에 참가하였다.

\section{2. 측정도구}

1) 압력 바이오 피드백 기구(Pressure bio feedback unit) 목빗근과 심부 목 굽힘근 의 일정한 수축력을 측정하기 위하여 압력 바이오 피드백 기구를 사용하였다. 압력 바이오 피드백 기구는 측정 기와 납작한 주머니 공기압 펌프로 구성되어 있으며, 심부 경부 근육 의 수축으로 인해 발생되는 힘이 압력 바이오 피드백 기구에 전달되 어 압력이 측정되고, 그 단위로는 $\mathrm{mmHg}$ 를 사용하였다.

\section{2) 초음파 촬영}

목빗근과 심부 목 굽힘근을 측정하기 위하여 Terason Ultrasound System (Teratech cooperation, USA)을 사용하였다. 근골격계 초음파 촬영 은 근육의 위축 및 비대 등을 검사할 수 있는 장비로써, 근육의 활성 패턴을 평가하고 선택적으로 목 주위 심부 근육 수축과 훈련 생체 되 먹임을 통한 훈련 방법의 교육과 수정을 위해 사용할 수 있다. ${ }^{14}$ 초음 파 촬영은 목빗근을 포함한 목의 심부 근육, 목동맥, 척추뼈 등의 혹 실한 형상이 보이도록 실시하였다.

초음파로 읽혀진 영상들은 NIH Image J software (version 1.44 for Windows)로 이미지화하여 목빗근과 심부 목 굽힘근의 근 두께를 측 정하였다. 이미지 분석프로그램으로 일반적인 이미지 작업뿐만 아니 라 이미지 상에서의 거리, 각도면적, 픽셀 값, 공간적 측정, 농도 등을 통계적으로 분석할수 있다. ${ }^{15,16}$

\section{3) 시선 각도 고정을 위한 지지대}

지지대는 대상자들의 시선의 각도를 고정하기 위해 지지대를 직접 제작한 것으로, 지지대의 관절 부위에 실험에 쓰일 각도를 표시하고 시선의 고정점을 부착하여 대상자들로 하여금 시선의 고정이 용이 하도록 고안하였다. 정면을 0 도로 시작하여 시선의 방향을 하방으로 20도, 40 도로 볼 수 있도록 설계하였다.

\section{3. 실험 절차}

\section{1) 시선의 각도에 따른 머리-목 굽힘 운동}

대상자는 바로 누운 자세에서 이마와 턱이 수평으로 올 수 있도록 중 립에 위치하도록 하고, 각도계는 모든 대상자의 눈꼬리를 기준점으 로 일치 하도록 맞추었다. 압력 피드백 기구를 대상자의 목의 뒷부분 에 위치시키고 대상자가 충분히 이완한 상태에서 압력계의 수치가 $20 \mathrm{mmHg}$ 를 유지하도록 설정했다. 시선의 각도는 총 3 단계로 0 도, 20 도, 40 도로 고정하였다. 각각의 각도에서 대상자는 설치된 각도계의 
시선 고정점에 압력 피드백 기구를 보도록 하고, $22 \mathrm{mmHg}$ 부터 시작 하여 $30 \mathrm{mmHg}$ 를 목표로 설정하여 $22 \mathrm{mmHg}, 24 \mathrm{mmHg}, 26 \mathrm{mmHg}$, $28 \mathrm{mmHg}, 30 \mathrm{mmHg}$ 까지 $2 \mathrm{mmHg}$ 씩 압력을 증가 시켰다. 각 단계에 서 10 초간 유지하도록 하고 총 다섯 단계로 압력을 순차적으로 증가 해 나가며 초음파 촬영을 실시하였다. 이때 대상자는 턱을 당기고 목 아래에 위치한 압력기구를 누르도록 하였다. 각 단계별 근 수축 과정 에서 대상자가 근피로를 유발하지 않도록 10 초간의 휴식 기간을 제 공하였다. 각 단계별 초음파 촬영은 3 장씩 수집하여 가장 해상도가 좋은 사진을 분석 자료에 사용하였다. ${ }^{17}$ 시선의 각도는 각도 고정을 위한 지지대를 이용하여 압력계를 고정한 후 시선의 각도에 맞추어 대상자가 시선을 조절할 수 있도록 하였다. 이때 시선의 움직임만을 허용하도록 목 관절의 움직임은 제한하고 압력계의 눈금이 움직이 지 않고 있음을 직접 확인하도록 하였다(Figure 1).

\section{2) 초음파 촬영 및 측정}

대상자들이 각 압력 수준을 유지하는 동안 목빗근과 심부 목 굽힘근 의 근육 두께를 측정하였다. 초음파의 전도자는 오른쪽 목에 종 방향 으로 적용하였으며, 기관(trachea)에서 평행하게 중심부의 바깥으로 5 $\mathrm{cm}$ 떨어진 곳으로 위치하도록 하였다. 초음파로 촬영한 영상들은 NIH Image J software (version 1.44 for Windows)로 이미지를 도출시켜 서 목빗근과 심부 목 굽힘근의 두께를 측정하였다. 모든 실험대상자 의 초음파촬영영상의 측정위치는 $0.5 \mathrm{~cm}$ 간격으로 총 세 개의 선을 그 어 측정위치를 정하였다. 각 대상자별로 척주판의 모양을 기준으로 근 두께 변화량이 두드러지는 지점에 기준선을 그은 후 $0.5 \mathrm{~cm}$ 간격으 로 좌, 우로 2 개의 선을 긋고 얻어진 3 개 선의 수치값 평균을 그 근육 의 두께로 계산하였다. 목빗근의 측정은 피하조직의 아래 부분에서 동맥의 위쪽 안쪽벽 가장자리까지, 심부 목 굽힘근은 동맥의 아래쪽 안쪽벽 가장자리까지로 측정하였다. 근육의 두께는 개인 간의 절대치

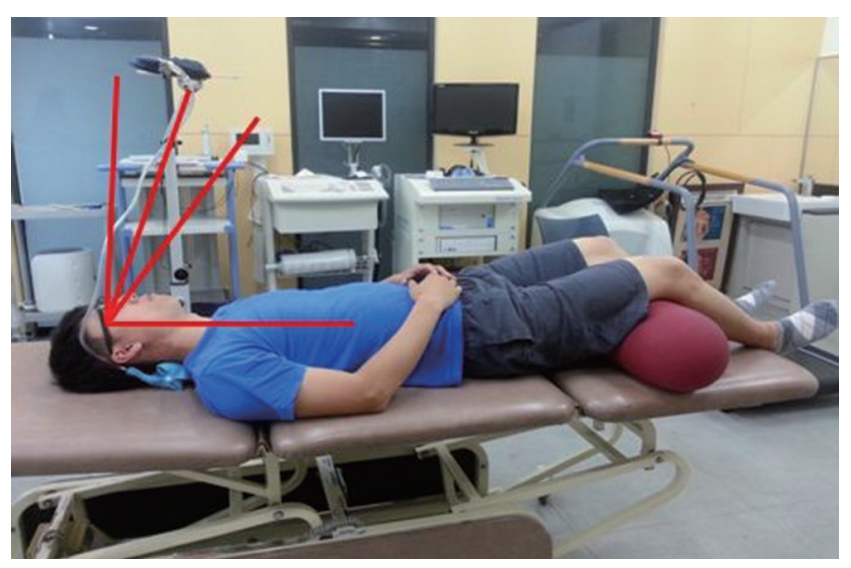

Figure 1. Experimental procedure for each level of neck pressure according to three different eye directions.
가 다르기 때문에 초음파를 통한 근육의 상태를 분석하기 위하여 수 축기의 근 두께에서 휴식기의 근 두께를 뺀 자료를 사용하였다.

\section{4. 자료 분석}

목빗근과 심부 경부 근육군에서 시선 각도와압력 수준에 따른 근육 두께의 차이를 비교 분석하기 위해 이요인 반복측정 분산분석(twoway ANOVA with repeated measurement)을 사용하였다. 집단-간 요인 은 시선의 각도로 집단-내 요인은 압력 수준을 독립변인으로 설정하 였고, 초음파를 통한 근육의 두께를 종속변인으로 설정하였다. 사후 분석으로는 집단-간 차이 비교는 Least Significance Difference (LSD) 를 사용하였고, 집단-내 대비 검정(tests of within-subjects contrasts)은 첫 $22 \mathrm{mmHg}$ 의 근육 두께를 기준으로 단순 대비 검정(simple contrasts)을 실시하였다. 모든 통계 처리는 윈도우용 SPSS 18.0을 사용하 였고 통계적 유의 수준은 $\alpha=.05$ 로 설정하였다.

\section{결 과}

본 연구에 참여한 대상자는 총 30 명으로 남자 12 명, 여자 18 명이었고, 평균 나이는 $22.83 \pm 1.49$ 세였다. 대상자의 일반적 특성으로 평균 신장 은 $167.83 \pm 8.84 \mathrm{~cm}$ 였고, 평균 몸무게는 $60.10 \pm 14.67 \mathrm{~kg}$ 이었다.

시선의 각도와 압력 수준에 따른 목빗근의 근육 두께 차이 변화를 분석하기 위한 이요인 반복측정분산분석의 결과, 시선 각도의 집단간 주효과 검정(between-subjects effect) 및 시선 각도와 압력 수준의 상호 작용(interaction effect)은 통계적으로 유의한 차이를 보이지 않 았다 $(\mathrm{p}>0.05)$. 그러나 압력 수준의 집단-내 주효과 검정(within-subjects effect)에서는 통계적으로 유의한 차이를 보였다 $(\mathrm{p}<0.001)$. 집단내 단순 대비 검정에서는 $22 \mathrm{mmHg}$ 와 $26 \mathrm{mmHg}, 28 \mathrm{mmHg}, 30 \mathrm{mmHg}$ 에서 통계적으로 유의한차이 변화를 보였다(Table 1).

시선의 각도와 압력 수준에 따른 심부 경부 근육군의 두께 차이 변화를 분석하기 위한 이요인 반복측정분산분석의 결과, 시선 각도 의 집단-간 주효과 검정 및 시선 각도와 압력 수준의 상호 작용은 통 계적으로 유의한 차이를 보이지 않았다 $(\mathrm{p}>0.05)$. 그러나 압력 수준의 집단-내 주효과 검정에서는 통계적으로 유의한 차이를 보였다 $(\mathrm{p}<0.001)$. 집단-내 단순 대비 검정에서는 $22 \mathrm{mmHg}$ 와 $24 \mathrm{mmHg}, 26$ $\mathrm{mmHg}, 28 \mathrm{mmHg}, 30 \mathrm{mmHg}$ 에서 통계적으로 유의한 차이 변화를 보 였다(Table 2).

\section{고 찰}

본 연구에서는 압력 바이오 피드백 기구를 사용해 서로 다른 시선 각 도에 따라 목 굽힘근의 두께가 어떻게 달라지는지를 비교하기 위해, 
Table 1. Comparison of sternocleidomastoid muscle thickness in levels of neck pressure according to three different eye directions

\begin{tabular}{|c|c|c|c|c|c|c|}
\hline & \multicolumn{6}{|c|}{ Level of neck pressure } \\
\hline & & $22 \mathrm{mmHg}$ & $24 \mathrm{mmHg}$ & $26 \mathrm{mmHg}$ & $28 \mathrm{mmHg}$ & $30 \mathrm{mmHg}$ \\
\hline \multirow[t]{3}{*}{ Eye direction } & $0^{\circ}$ & $0.310 \pm 0.068$ & $0.316 \pm 0.080$ & $0.320 \pm 0.088$ & $0.319 \pm 0.079$ & $0.319 \pm 0.087$ \\
\hline & $20^{\circ}$ & $0.310 \pm 0.083$ & $0.316 \pm 0.086$ & $0.327 \pm 0.091$ & $0.327 \pm 0.090$ & $0.332 \pm 0.099$ \\
\hline & $40^{\circ}$ & $0.332 \pm 0.086$ & $0.326 \pm 0.078$ & $0.341 \pm 0.079$ & $0.348 \pm 0.094$ & $0.356 \pm 0.106$ \\
\hline \multirow[t]{3}{*}{$p$-value } & Between-subj & & \multicolumn{4}{|c|}{$F_{(1,87)}=0.694, p=0.502$} \\
\hline & Within-subjec & & \multicolumn{4}{|c|}{$F_{(4,348)}=5.085, p=0.001$} \\
\hline & Interaction eff & & \multicolumn{4}{|c|}{$F_{(1,348)}=0.889, p=0.526$} \\
\hline
\end{tabular}

${ }^{*} p<0.05$.

Table 2. Comparison of deep cervical flexor muscles thickness in levels of neck pressure according to three different eye directions

\begin{tabular}{|c|c|c|c|c|c|c|}
\hline & \multicolumn{6}{|c|}{ Level of neck pressure } \\
\hline & & $22 \mathrm{mmHg}$ & $24 \mathrm{mmHg}$ & $26 \mathrm{mmHg}$ & $28 \mathrm{mmHg}$ & $30 \mathrm{mmHg}$ \\
\hline \multirow[t]{3}{*}{ Eye direction } & $0^{\circ}$ & $0.462 \pm 0.073$ & $0.474 \pm 0.075$ & $0.477 \pm 0.072$ & $0.479 \pm 0.087$ & $0.486 \pm 0.083$ \\
\hline & $20^{\circ}$ & $0.474 \pm 0.086$ & $0.478 \pm 0.089$ & $0.484 \pm 0.084$ & $0.488 \pm 0.081$ & $0.490 \pm 0.087$ \\
\hline & $40^{\circ}$ & $0.480 \pm 0.083$ & $0.484 \pm 0.085$ & $0.488 \pm 0.086$ & $0.498 \pm 0.082$ & $0.496 \pm 0.089$ \\
\hline \multirow[t]{3}{*}{$p$-value } & Between-subjects effect & & \multicolumn{4}{|c|}{$F_{(1,87)}=0.206, p=0.814$} \\
\hline & Within-subjects effect* & & \multicolumn{4}{|c|}{$F_{(4,348)}=12.260, p<0.001$} \\
\hline & Interaction effect & & \multicolumn{4}{|c|}{$F_{(1,348)}=0.439, p=0.897$} \\
\hline
\end{tabular}

${ }^{*} p<0.05$.

머리-목 굽힘 운동을 누운 자세에서 적용시킨 후 초음파를 통해 근 두께의 변화를 측정 및 관찰하였다. 심부 목 굽힘 근육들은 직접 촉 진하거나 표면 근전도를 적용하기는 어렵기 때문에, 근육의 속성 변 화 관찰을 위해 초음파 촬영의 측정 도구를 이용하여 근수축의 과정 을 실시간으로 확인할 수 있어 사용하였다. ${ }^{18}$ 머리-목 굽힘 검사는 목 뒤에 공기로 채워진 압력 바이오 피드백 기구의 압력기를 놓고 심부 목 굽힘근의 수축으로 목뼈의 앞굽이를 감소시켜 점진적으로 목을 평평하게 유지하는 것을 관찰하는 것이므로, 표면근인 목빗근과 심 부근인 목긴근의 해부학적 활동을 평가하는 데 적합하다. ${ }^{2,17}$ 따라서 본 연구에서는 근육의 두께를 관찰하기 위해 이와 같은 방법을 이용 하였다.

본 연구에서 시선에 따른 압력 수준별 목빗근의 근 두께 변화량을 살펴 보면, 0 도와 20 도의 시선 각도에서는 $22 \mathrm{mmHg}$ 와 비교하여 24 $\mathrm{mmHg}$ 에서부터 $30 \mathrm{mmHg}$ 까지 통계적으로 유의한 수준의 변화를 보 였고, $24 \mathrm{mmHg}$ 에서부터 $30 \mathrm{mmHg}$ 까지는 비슷한 근 두께의 양상을 보였다. 40에서는 $26 \mathrm{mmHg}$ 에서부터 $30 \mathrm{mmHg}$ 까지의 압력 변화에서 통계적으로 유의한 차이를 나타냈다. 따라서 전반적으로 목 부위 압 력이 $24 \mathrm{mmHg}$ 부터 점차 증가할수록 근육의 두께가 증가하는 양상 을 보였다. 또한 같은 압력의 분포에서는 시선의 각도가 높을수록 근 육의 두께가 두꺼워진다는 것을 확인하였다. Falla 등 ${ }^{19}$ 의 연구에서 제 시한 바와 같이 압력의 증가와 근 활성의 증가량은 양의 상관관계가 있다고 하였다. Hodge 등 ${ }^{20}$ 은 초음파를 통한 근 활성 측정을 위해서 는 근육의 근속각(penneationangle), 근 두께, 근속 길이(facsicle length)
의 변화로만 확인할 수 있다고 제시하였다. 이것은 근육이 연속된 탄 력성 성분의 비로 구성되어 있기 때문에, 근육의 형태와 활동과의 관 계는 근육의 길이 변화에 의존하게 될 것이라는 근거에서 비롯된다. 이러한 결과와 본 연구 결과를 미루어 볼 때, 시선을 아래로 향하는 것이 근육의 활성도를 줄일 수 있는 것으로 보여진다.

시선의 각도에 따른 압력 수준별 심부 목 굽힘근의 근 두께 변화량 의 결과에서, 0 도, 20 도, 40 도 모두에서 $22 \mathrm{mmHg}$ 부터 $30 \mathrm{mmHg}$ 까지 지속적인 근 두께의 증가를 보여주고 있으며, $22 \mathrm{mmHg}$ 의 압력에 비 해 $24 \mathrm{mmHg}$ 부터 $30 \mathrm{mmHg}$ 까지 모든 압력 차이에 따라 통계적 유의 성이 있는 것으로 나타났다. 이는 압력의 증가에 따른 심부 목 굽힘근 의 근 두께 변화량이 증가하였다는 Jun ${ }^{14}$ 의 연구와 일치하는 결과를 보였다. 또한 목빗근의 결과와 같이 동일한 압력의 분포에서는 시선 의 각도가 높을수록 근육의 두께가 두꺼워지는 결과를 보였다. 선행 연구에서는 목에 적용하는 힘, 압력, 근 활성도를 근전도를 사용하거 나 압력 바이오 피드백 기구를 이용하여 심부 목 굽힘근을 측정하였 고, 또 다른 선행연구에서는 초음파를 이용하여 목의 근육을 관찰 및 측정 하기도 하였다.1721,22 그러나 시선의 각도에 따른 근 두께 변화 량차이에 대한 연구는 부족하였고, 이에 본 연구에서는 시선의 각도 별 목빗근과 심부 목 굽힘근의 두께 변화량의 차이를 측정하였다. 그 결과 두 근육 모두 시선을 정면으로 하였을 때보다 시선이 아래쪽을 향했을 때, 근 두께 변화량이 적었음을 확인 할 수 있었다. 또한 그 변 화량은 40 도에서보다 20 도에서 더 적은 변화량을 보였다. 이는 미국 산업안전보건청(Occupational Safety \& Health Administration; 1991)과 
캐나다 국립표준협회(Canadian Standard Association; 1989)에서 제시 한 결과와 같은 것으로, 컴퓨터 모니터가 시선 높이에서 수직선상으 로 2-15도 정도 기울어진 위치에 놓여 질 때 목 근육들의 자세적인 부 하를 줄일 수 있다고 한 것과 일치한다. 또한 $\operatorname{Kumar}^{11}$ 의 연구에서 컴 퓨터 모니터의 중심부가 눈의 수평선상에서 35 도 이하로 기울어졌을 때 목빗근의 근 활성도가 낮게 나타난 결과와 Turville ${ }^{12}$ 의 연구에서 눈의 수평선상에서 컴퓨터 모니터의 중심부까지의 시선의 각도가 40 도에서 근 활성도와 근 피로도가 떨어진다고 한 내용과 유사하다.

본 연구 결과에서는 시선의 각도를 아래로 향하는 것만으로도 같 은 수준의 움직임을 유도할 수 있어서 근육의 적은 활성화로도 목적 에 맞는 근 수축을 이끌어 낼 수 있었다. 이를 통하여 정상인이나 머 리와 목의 움직임에 문제가 있는 환자의 목 조절에 있어 시선의 각도 가 중요한 역할을 하고, 치료와 교육을 통하여 시선의 각도의 설정을 통하여 머리-목의 움직임 조절 뿐만 아니라 목 근육의 손상을 예방 할 수 있다. 향후 정상인이 아닌 목에 통증이 있거나 목의 근력이 떨 어지는 근골격계 또는 신경계적인 질환을 않고 환자들을 대상으로 머리-목 움직임에 대한 연구와 시선이 머리-목 움직임에 어떠한 영향 을 주는지에 대해 연구가 더 필요할 것이다.

\section{REFERENCES}

1. Conley MS, Meyer RA, Bloomberg JJ, et al. Noninvasive analysis of human neck muscle function. Spine (Phila Pa 1976). 1995;20(23):2505-12.

2. Mayoux-Benhamou MA, Revel M, Vallee C, et al. Longus colli has a postural function on cervical curvature. Surg Radiol Anat. 1994;16(4):367-71.

3. Vasavada AN, Li S, Delp SL. Influence of muscle morphometry and moment arms on the moment-generating capacity of human neck muscles. Spine (Phila Pa 1976). 1998;23(4):412-22.

4. Falla D, Bilenkij G, Jull G. Patients with chronic neck pain demonstrate altered patterns of muscle activation during performance of a functional upper limb task. Spine (Phila Pa 1976). 2004;29(13):1436-40.

5. Rezasoltani A, Ylinen J, Vihko V. Isometric cervical extension force and dimensions of semispinalis capitis muscle. J Rehabil Res Dev. 2002; 39(3):423-8.

6. Lee JA, Kim SY. Reliability of ultrasonography for the longus colli in asymptomatic subjects. J Kor Phys Ther. 2011;23(4):59-66.
7. Lee HJ, Kim MK, Ha HK, et al. Comparison of muscle architecture of lower extremity using rehabilitative ultrasound image in young adults: A comparative study of muscle cross-sectional area of lower extermity of Seoul and Hanoi in Vietnam. J Kor Phys Ther. 2014;26(5):324-30.

8. Greig AM, Straker LM, Briggs AM. Cervical erector spinae and upper trapezius muscle activity in children using different information technologies. Physiotherapy. 2005;91(2):119-26.

9. Administration OSaH. Working safely with video display terminal. 1991. 10. Association CS. A guideline to office ergonomics. 1989.

11. Kumar S. A computer desk for bifocal lens wearers, with special emphasis on selected telecommunication tasks. Ergonomics. 1994;37(10): 1669-78.

12. Turville KL, Psihogios JP, Ulmer TR, et al. The effects of video display terminal height on the operator: A comparison of the 15 degree and 40 degree recommendations. Appl Ergon. 1998;29(4):239-46.

13. Park HJ. Eye functiona test and refactor test for optician. Hyunmoon, 2001.

14. Jun DH. Effect of arm movement with cranio-cervical flexion test on muscle activity. Daegu University. Dissertation of Master's Degree. 2012.

15. Amaro A, Amado F, Duarte JA, et al. Gluteus medius muscle atrophy is related to contralateral and ipsilateral hip joint osteoarthritis. Int J Sports Med. 2007;28(12):1035-9.

16. Koppenhaver SL, Hebert JJ, Fritz JM, et al. Reliability of rehabilitative ultrasound imaging of the transversus abdominis and lumbar multifidus muscles. Arch Phys Med Rehabil. 2009;90(1):87-94.

17. Jull G, Kristjansson E, Dall'Alba P. Impairment in the cervical flexors: A comparison of whiplash and insidious onset neck pain patients. Man Ther. 2004;9(2):89-94.

18. Cagnie B, Derese E, Vandamme L, et al. Validity and reliability of ultrasonography for the longus colli in asymptomatic subjects. Man Ther. 2009; 14(4):421-6.

19. Falla D, Jull G, Dall'Alba P, et al. An electromyographic analysis of the deep cervical flexor muscles in performance of craniocervical flexion. Phys Ther. 2003;83(10):899-906.

20. Hodges PW, Pengel LH, Herbert RD, et al. Measurement of muscle contraction with ultrasound imaging. Muscle Nerve. 2003;27(6):682-92.

21. Falla DL, Jull GA, Hodges PW. Patients with neck pain demonstrate reduced electromyographic activity of the deep cervical flexor muscles during performance of the craniocervical flexion test. Spine (Phila Pa 1976). 2004;29(19):2108-14.

22. Yun KH, Kim K. Effect of craniocervical flexion exercise using sling on thickness of sternocleidomastoid muscle and deep cervical flexor muscle. J Kor Soc Phys Med. 2013;8(2):253-61. 